\title{
A Cephalometric Study of FH-SN Angle in Different Sagittal Skeletal Patterns among Patients Seeking Orthodontic Treatment
}

\section{Rajan Singh ${ }^{1}$, Avinash Chaudhary ${ }^{2 *}$, Basanta K Shrestha ${ }^{3}$, Deependra Prasad Sarraf ${ }^{4}$ and Pankaj Shah ${ }^{5}$}

${ }^{1}$ Senior Resident, Department of Orthodontics, Chitwan Medical College, Chitwan, Nepal

${ }^{2}$ Senior Resident, Department of Orthodontics, College of Dental Surgery, B.P. Koirala Institute of Health Sciences, Dharan, Nepal

${ }^{3}$ Professor, Head of Department, Orthodontics and Dentofacial Orthopedics Unit, Department of Dentistry, Tribhuvan University Teaching Hospital, Kathmandu, Nepal ${ }^{4}$ Associate Professor, Department of Clinical Pharmacology and Therapeutics, B.P. Koirala Institute of Health Sciences, Dharan, Nepal

${ }^{5}$ Post Graduate Resident, Department of Prosthodontics and Crown-Bridge, College of Dental Surgery, B.P. Koirala Institute of Health Sciences, Dharan, Nepal

*Corresponding Author: Avinash Chaudhary, Senior Resident, Department of Orthodontics, College of Dental Surgery, B.P. Koirala Institute of Health Sciences, Dharan, Nepal.
Received: October 16, 2020

Published: October 31, 2020

(C) All rights are reserved by Avinash

Chaudhary., et al.

\begin{abstract}
Introduction: Frankfort horizontal (FH) plane and Sella-Nasion (SN) plane are commonly used reference planes in orthodontic cephalometry. Any variation in this angulation from its accepted 7 degree can affect the cephalometric diagnosis. The objective of the study was to determine an average FH-SN angle among patients seeking orthodontic treatment.

Materials and Methods: One hundred lateral cephalograms were obtained from the records of patients who came for orthodontic treatment in Orthodontics and Dentofacial Orthopaedic Unit. Cephalometric tracing was done on acetate tracing paper of 0.004 inch thick using $3 \mathrm{H}$ pencil of $0.5 \mathrm{~mm}$. Mean and standard deviation of FH-SN angle of the samples was calculated. One way analysis of variance and independent-samples t-test were used for assessing the relationship between dependent and independent variables at P-value of 0.05 .

Results: Average FH-SN angle was found to be $7.57^{\circ}\left(\mathrm{SD}=2.57^{\circ}\right)$. FH-SN angle was found to be $7.97^{\circ}\left(\mathrm{SD}=2.66^{\circ}\right)$ in $\mathrm{Class}$ I subjects, $7.44^{\circ}\left(\mathrm{SD}=3.10^{\circ}\right)$ in Class II subjects and $7.25^{\circ}\left(\mathrm{SD}=2.45^{\circ}\right)$ in Class III subjects. FH-SN angle did not vary significantly among different sagittal skeletal patterns ( $\mathrm{P}$ value $>0.05$ ). There was no gender variation of FH-SN angle (P value $>0.05$ ). The angle between the posterior vertical maxillary plane and Frankfort plane $(\mathrm{PM}-\mathrm{FH})$ was found to be $102.94^{\circ}\left(\mathrm{SD}=5.10^{\circ}\right)$ in $\mathrm{Class}$ I subjects, $102.57^{\circ}(\mathrm{SD}$ $\left.=4.64^{\circ}\right)$ in Class II subjects and $103.62^{\circ}\left(\mathrm{SD}=4.23^{\circ}\right)$ in Class III subjects. Similarly, the angle between the posterior vertical maxillary plane and sella-nasion plane (PM-SN) was found to be $110.91^{\circ}\left(\mathrm{SD}=6.07^{\circ}\right)$ in Class I subjects, $110.01^{\circ}\left(\mathrm{SD}=5.07^{\circ}\right)$ in $\mathrm{Class}_{\mathrm{II}}$ subjects and $110.88^{\circ}\left(\mathrm{SD}=4.30^{\circ}\right)$ in Class III subjects.

Conclusion: The average FH-SN angle was found to be $7.57^{\circ}\left(\mathrm{SD}=2.57^{\circ}\right)$. There was no variation in FH-SN angle in different sagittal skeletal patterns. FH-SN angle did not exhibit sexual dimorphism. The use of the PM line in evaluating the positioning of the horizontal FH and SN planes can help us establish which of the two planes is more reliable.

Keywords: Cephalometric Study; FH-SN Angle; Variation; Sagittal Skeletal Patterns; Posterior Vertical Maxillary Plane
\end{abstract}




\section{Introduction}

Cranial base inclination and possible consequences on the development of malocclusion have been studied for many years and different hypotheses have been discussed [1-5]. An understanding of craniofacial anatomy is considered the fundamental basis of orthodontic practice. Frankfort horizontal plane (FH) and the anterior cranial base (sella to nasion line [SN]) are the commonly used reference planes or lines for orientation in the routine cephalometric evaluation of orthodontic and/or orthognathic surgery patients. The relationship between these two reference planes (FH and SN) was demonstrated in 1957 by Daugaard-Jensen, who registered in her collective an almost constant mean angle of $7^{\circ}$ during growth [6]. The literature suggests that the angle between these lines is relatively constant at $7^{\circ}$ and the true horizontal axis or constructed $\mathrm{FH}$ is obtained by tracing a line in a clockwise direction approximately $7^{\circ}$ from SN [7-9]. However, this constancy has not yet been sufficiently proven by reliable evidence.

The angle between $\mathrm{FH}$ and $\mathrm{SN}$ is assumed to be $7^{\circ}$ and any variation from this can affect the cephalometric diagnosis. However, this constancy has not yet been sufficiently proven. Hence, assessment of FH-SN angle is essential before drawing any cephalometric conclusion. There is paucity of data on variation on FH-SN angle in Nepalese patients. Therefore, this study was carried out to determine average FH-SN angle among patients seeking orthodontic treatment.

\section{Materials and Methods}

A cross-sectional study was conducted among 100 patients at Orthodontics and Dentofacial Orthopedic Unit, Department of Dentistry, Institute of Medicine, Tribhuvan University Teaching Hospital, Kathmandu, Nepal. The patients who were 16 years and above, who had varying degrees of skeletal and/or dentoalveolar malocclusions, who had never received previous orthodontic treatment and with complete diagnostic records including availability of good quality cephalometric radiographs were enrolled in the study. Patients having subjects with congenital anomalies/syndromes and marked asymmetries, previous history of trauma to face and neck region, poor quality radiograph with image distortion and previous surgery involving jaws were excluded. Ethical clearance [165(6-11E)2/073/074] was obtained from the Institutional Review Board, Institute of Medicine.

One hundred lateral cephalograms were obtained from the records of the enrolled patients. Age, gender, malocclusions (Class I, II and III), FH-SN angle, PM-FH angle and PM-SN angle were recorded on a self-designed proforma. Six parameters, namely Beta angle, $\mathrm{W}$ angle, Wits appraisal, FH-SN angle, PM-FH angle and PM-SN angle were measured. Three parameters, namely Beta angle, $\mathrm{W}$ angle and Wits appraisal using best of three method were used for determination of sagittal skeletal discrepancy. FH-SN angle was measured to know any variation in FH-SN angle in different sagittal skeletal classes, i.e. Class-I, Class-II and Class-III malocclusions. The angles made by posterior vertical maxillary plane (PM) with FH plane (i.e. PM-FH) and SN plane (i.e. PM-SN) were measured. The evaluation of lateral cephalograms was carried on the x-ray view box using cephalometric protractor (ormocepha; Ormco Corporation, 13K27, 760-0000) on acetate tracing paper of 0.004 inch thick using $3 \mathrm{H}$ pencil of $0.5 \mathrm{~mm}$. Cephalometric Landmarks are shown in the figure $1 \mathrm{a}$ and $1 \mathrm{~b}$.
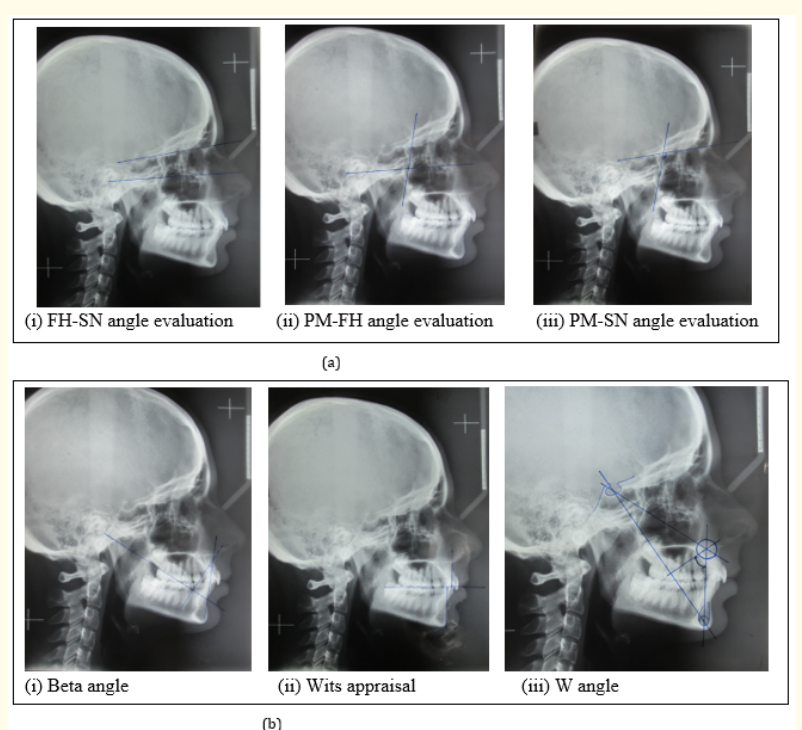

Figure 1a and 1b: Cephalometric landmarks.

Twenty five percent of the samples were randomly selected and remeasured after 2 weeks to measure the reliability. Intraclass correlation coefficient was performed to check for intra observer agreement. The data were entered into Microsoft excel 2010. Mean, standard deviation, frequency and percentage were calculated. Intraclass correlation coefficient was used to assess the intraobserver reliability. One way analysis of variance (ANOVA) was used for assessing the relationship between sagittal skeletal class I, II and III malocclusion and FH-SN angle. Independent samples t-test was 
performed to assess the association between gender related difference on FH-SN angle. The reliability of the method was analyzed using Dahlberg's formula that determined the method error [10]. The statistical analyses were performed using the SPSS program, version 21 (SPSS Inc, Chicago).

\section{Results}

Out of 100 patients, 56 were male. Age of the patients ranged from 16 - 40 years. Mean age of the patients was $20.59 \pm 4.493$ year. Average $\mathrm{FH}-\mathrm{SN}$ angle was $7.57^{\circ} \pm 2.754^{\circ}$. FH-SN angle was smallest $\left(7.258^{\circ}\right)$ in Class III and largest $\left(7.971^{\circ}\right)$ in Class I malocclusion (Table 1).

\begin{tabular}{|c|c|c|c|c|}
\hline $\begin{array}{l}\text { Sagittal skeletal } \\
\text { patterns }\end{array}$ & $\mathbf{N}$ & $\begin{array}{c}\text { Mean } \\
\text { (Degree) }\end{array}$ & $\begin{array}{c}\text { SD } \\
\text { (Degree) }\end{array}$ & P-value \\
\hline Class I & 35 & 7.971 & 2.667 & \multirow[t]{3}{*}{$0.549 *$} \\
\hline Class II & 34 & 7.441 & 3.106 & \\
\hline Class III & 31 & 7.258 & 2.459 & \\
\hline
\end{tabular}

Table 1: Distribution of FH-SN angle in different sagittal skeletal pattern $(n=100)$.

*Not significant (ANOVA test, P-value > 0.05).

The FH-SN angle does not vary significantly among different sagittal skeletal patterns i.e. in Class I, Class II and Class III ( $p$ > 0.05). So, the Null Hypothesis was accepted as there was no variation of FH-SN angle in different sagittal skeletal patterns ( $p>0.05$ ). FH-SN angle doesn't exhibit sexual dimorphism (Table 2).

\begin{tabular}{|l|c|c|c|c|}
\hline Gender & N & Mean (Degree) & SD & P-value \\
\cline { 1 - 4 } Male & 44 & 7.307 & 2.590 & \multirow{2}{*}{$0.400^{*}$} \\
\cline { 1 - 4 } Female & 56 & 7.777 & 2.882 & \\
\hline
\end{tabular}

Table 2: Gender wise variation of FH-SN angle ( $\mathrm{n}=100)$.

*Not significant (independent sample t test, P-value > 0.05).

The angle between the posterior vertical maxillary plane and Frankfort plane (PM-FH) in male subjects was found to be $103.34^{\circ}$ $\pm 4.65^{\circ}$ and in female subjects it was found to be $102.78^{\circ} \pm 4.69^{\circ}$. Similarly, the angle between posterior vertical maxillary plane and sella-nasion plane (PM-SN) in male subjects was found to be $110.64^{\circ} \pm 5.42^{\circ}$ and in female subjects it was found to be $110.56^{\circ}$ $\pm 5.06^{\circ}$ (Table 3 ).

The angle between the posterior vertical maxillary plane and Frankfort plane (PM-FH) in Class I subjects was found to be $102.94^{\circ}$ $\pm 5.10^{\circ}$, in Class II subjects it was $102.57^{\circ} \pm 4.64^{\circ}$ and in Class III subjects it was $103.62^{\circ} \pm 4.23^{\circ}$. The angle between the posterior vertical maxillary plane and sella-nasion plane (PM-SN) in Class I subjects was found to be $110.91^{\circ} \pm 6.07^{\circ}$, in Class II subjects it was $110.01^{\circ} \pm 5.07^{\circ}$ and in Class III subjects it was $110.88^{\circ} \pm 4.30$ (Table 4).

\begin{tabular}{|l|c|c|c|c|}
\hline \multirow{2}{*}{ Variables } & \multicolumn{2}{|c|}{ Male } & \multicolumn{2}{c|}{ Female } \\
\cline { 2 - 5 } & Mean & SD & Mean & SD \\
\hline PM-FH & 103.341 & 4.567 & 102.786 & 4.695 \\
\hline PM-SN & 110.648 & 5.422 & 110.563 & 5.065 \\
\hline
\end{tabular}

Table 3: Gender wise variation of PM-FH and PM-SN angles.

\begin{tabular}{|l|c|c|c|c|c|}
\hline \multirow{2}{*}{$\begin{array}{l}\text { Sagittal skeletal } \\
\text { patterns }\end{array}$} & \multirow{2}{*}{ Number } & \multicolumn{2}{|c|}{ PM-FH } & \multicolumn{2}{c|}{ PM-SN } \\
\cline { 3 - 6 } & & Mean & SD & Mean & SD \\
\hline Class-I & 35 & 102.94 & 5.10 & 110.91 & 6.07 \\
\hline Class-II & 34 & 102.57 & 4.64 & 110.01 & 5.07 \\
\hline Class-III & 31 & 103.62 & 4.23 & 110.88 & 4.30 \\
\hline
\end{tabular}

Table 4: Variation of PM-FH and PM-SN angles in different sagittal skeletal patterns.

Intraclass correlation coefficients for FH-SN, PM-FH, PM-SN, Beta angle, W angle and Wits appraisal were 0.989, 0.991, 0.987, $0.946,0.972$ and 0.969 respectively. This indicated excellent intraobserver agreement for all the variables (Table 5).

\begin{tabular}{|l|c|c|c|}
\hline \multirow{2}{*}{ Parameters } & \multirow{2}{*}{$\begin{array}{c}\text { Intraclass } \\
\text { Correlation }\end{array}$} & \multicolumn{2}{|c|}{$\mathbf{9 5 \% \text { Confidence Interval }}$} \\
\cline { 3 - 4 } & & Lower Bound & Upper Bound \\
\hline FH-SN & 0.989 & 0.961 & 0.996 \\
\hline PM-FH & 0.991 & 0.973 & 0.997 \\
\hline PM-SN & 0.987 & 0.967 & 0.995 \\
\hline Beta angle & 0.946 & 0.560 & 0.985 \\
\hline W angle & 0.972 & 0.923 & 0.989 \\
\hline Wits appraisal & 0.969 & 0.578 & 0.992 \\
\hline
\end{tabular}

Table 5: Intraclass correlation coefficients for intraobserver reliability.

Method error was calculated using Dahlberg formula. The method error for the variables were between 0.461-1.063 (Table 6).

\begin{tabular}{|l|c|}
\hline Parameters & Method error \\
\hline W angle & 1.063 \\
\hline Beta angle & 0.945 \\
\hline Wits appraisal & 1.042 \\
\hline FH-SN angle & 0.461 \\
\hline PM-FH angle & 0.612 \\
\hline PM-SN angle & 0.680 \\
\hline
\end{tabular}

Table 6: Dahlberg test for assessing method error. 


\section{Discussion}

A reliable reference plane is vital to any radiographic cephalometric study. Reference planes are useful mainly for two purposes. A certain reference plane may be appropriate for one purpose but inappropriate for the other. The mean FH-SN angle in the study was found to be $7.57^{\circ} \pm 2.75^{\circ}$ which is very close to the generally accepted $7^{\circ}$ advocated in various studies [6-9].

The average FH-SN angle of female subjects of this study was slightly greater than that of male subjects. However, this difference was not found to be statistically significant. FH-SN angle did not exhibit sexual dimorphism in the study.

FH-SN angle was found to be $7.97^{\circ} \pm 2.66^{\circ}$ in Class I subjects, $7.44^{\circ} \pm 3.10^{\circ}$ in Class II subjects and $7.25^{\circ} \pm 2.45^{\circ}$ in Class III subjects and the difference was statistically non-significant. However, Hasan., et al. found that FH-SN angle was increased significantly in the Class II group $\left(10.20^{\circ} \pm 3.35^{\circ}\right)$ compared to Class I $\left(8.32^{\circ} \pm\right.$ $\left.4.27^{\circ}\right)$ and Class III $\left(8.00^{\circ} \pm 3.20^{\circ}\right)$ groups [11]. Also, Alves., et al. found an increased FH-SN angle in skeletal Class II $\left(8.42^{\circ} \pm 2.2^{\circ}\right)$ compared to skeletal Class III $\left(7.71^{\circ} \pm 3.4^{\circ}\right)$ [12]. Polat., et al. found increased FH-SN angle in Class III group $\left(10.6^{\circ} \pm 3.34^{\circ}\right)$ compared to Class I group $\left(7.77^{\circ} \pm 1.88^{\circ}\right)$ and Class II Div 1 group $\left(8.02^{\circ} \pm\right.$ $2.59^{\circ}$ ) [13]. These variations could be due to racial difference and case selection procedures; particularly the ANB angle (for grouping into skeletal classes) may be a confounding factor, because $\mathrm{N}$ (Nasion) point is common to both FH-SN angle and ANB angle. In this study ANB angle was not used; instead, Beta angle, $\mathrm{W}$ angle and Wits appraisal were measured and best of three method was applied to determine the sagittal skeletal Classes. In none of the cases, the three parameters gave three different sagittal skeletal patterns. In Class II malocclusion, the cranial base angle and length were found significantly greater among Whites but not among Asians $[14,15]$. Therefore, ethnic differences in genetic background and environmental context may play a role in cranial base morphology. Differences in natural head posture, evolutionary history and genetic origin might contribute to the difference in cranial base orientation and flexure [16].

Variation in FH-SN angle could be due to change in inclination of $\mathrm{SN}$ line, FH line or both. If variation of FH-SN angle is due to variation in SN line, cephalometric parameters which use FH line alone should be used for making cephalometric diagnosis but cephalometric reference planes tend to be highly variable and poorly related, hence, cephalometric analysis should be performed using more than one reference plane as stated by Madsen., et al. in 2008 [17]. Alternatively, corrected "norms" for SNA and SNB advocated by Moore in 1976 when SN plane is not reliable [18].

In this study, the posterior vertical maxillary (PM) line was used for evaluating the positioning of FH and SN plane. The angle between the posterior vertical maxillary plane and Frankfort plane (PM-FH) in the study subjects was found to be higher than those proposed by Riolo., et al. and Veronica., et al. [19,20] our study had some limitations. The study did not include ethnic variation. Larger sample size would have been better.

\section{Conclusion}

The average FH-SN angle was found to be 7.570 with standard deviation of 2.750. There was no variation in FH-SN angle in different sagittal skeletal patterns. FH-SN angle did not exhibit sexual dimorphism. The use of the PM line in evaluating the positioning of the horizontal FH and SN planes can help us establish which of the two planes is more reliable.

\section{Financial Support and Sponsorship}

Nil.

\section{Conflict of Interest}

None.

\section{Bibliography}

1. Bjork A. "Cranial base development". American Journal of Orthodontics (1955): 41.

2. Ricketts R. "Facial and denture changes during orthodontic treatment as analyzed from the temporomandibular joint". Journal of Maxillofacial and Oral Surgery (1971): 4.

3. Moss M. "Correlation of cranial base angulation with cephalic malformations and growth disharmonies of dental interest". The New York State Dental Journal (1955): 21.

4. Bjork A. "Some biological aspects of prognathism and occlusion of the teeth". Acta Odontologica Scandinavica (1950): 9.

5. Renfroe E. "A study of the facial patterns associated with class I, class II, division 1 and class II, division 2 malocclusion". The Angle Orthodontist (1948): 18.

6. Daugaard-Jensen I. "Cephalometrics orthodontics and facial aesthetics". Transactions of the European Orthodontic Society (1957). 
7. GA Hack., et al. "Long-term stability and prediction of soft tissue changes after LeFort I surgery". American Journal of Orthodontics (1993): 104.

8. Greiner P., et al. "The angle between the Frankfort horizontal and the sella-nasion line". The Journal of Orofacial Orthopedics (2004): 65.

9. Mobarak KA., et al. "Soft tissue profile changes following mandibular advancement surgery: predictability and long-term outcome". American Journal of Orthodontics (2001): 119.

10. Kim HY. "Statistical notes for clinical researchers: Evaluation of measurement error 2: Dahlberg's error, Bland-Altman method, and Kappa coefficient". Restorative Dentistry and Endodontics 38.3 (2013): 182-185.

11. Hasan Kamak., et al. "Cranial base features between sagittal skeletal malocclusions in Anatolian Turkish adults: Is there a difference?" Journal of Orthodontic Research 1 (2013): 52-56.

12. Alves PV., et al. "Cranial base angulation in Brazilian patients seeking orthodontic treatment". Journal of Craniofacial Surgery 19 (2008): 334-338.

13. 0"0 Polat and B Kaya. "Changes in cranial base morphology in different malocclusions". Orthodontics and Craniofacial Research 10 (2007): 216-221.

14. Mona Aly Abbassy., et al. "Comparative cephalometric study of Class I malocclusion in Egyptian and Japanese adult females". Orthodontic Waves 71 (2012): 59-65.

15. Gong A. "Cranial base characteristics in anteroposterior malocclusions: A meta-analysis". The Angle Orthodontist 86 (2016): 668-680.

16. Kuroe K. "Variation in the cranial base orientation and facial skeleton in dry skulls sampled from three major populations". European Journal of Orthodontics 26 (2004): 201-207.

17. Madsen D. "Craniofacial reference plane variation and natural head position". European Journal of Orthodontics 30 (2008): 532-540.

18. Moore J. "Variation of the sella-nasion plane and its effect on SNA and SNB". Journal Oral Surgery (1976): 34.

19. Riolo ML., et al. "An atlas of craniofacial growth: cephalometric standards from the University School Growth Study. Ann Arbor, MI: University of Michigan (1974).
20. Veronica Incisivo and Alessandro S. "The Reliability and Variability of SN and PFH Reference Planes in Cephalometric Diagnosis and Therapeutic Planning of Dentomaxillofacial Malformations". The Journal of Craniofacial Surgery 11 (2000): 31-38.

\section{Assets from publication with us}

- Prompt Acknowledgement after receiving the article

- Thorough Double blinded peer review

- Rapid Publication

- Issue of Publication Certificate

- High visibility of your Published work

Website: $\underline{w w w}$.actascientific.com/

Submit Article: www.actascientific.com/submission.php

Email us: editor@actascientific.com

Contact us: +919182824667 